\title{
Textured Development of Feeble Magnetic Ceramics by Colloidal Processing Under High Magnetic Field
}

\author{
Yoshio SAKKA and Tohru S. SUZUKI \\ National Institute for Materials Science, 1-2-1, Sengen, Tsukuba-shi, Ibaraki 305-0047 \\ 強磁場コロイドプロセスによる弱磁性セラミックスの配向 \\ 目 義雄·鈴木 達 \\ 物質・材料研究機構材料研究所, 305-0047 つくば市千現 1-2-1
}

\begin{abstract}
The controlled development of texture is one of the ways for effectively improving physical and mechanical properties. In this review paper, we introduce a new processing of textured ceramics with a feeble magnetic susceptibility by slip casting in a high magnetic field and subsequent heating. As an example of feeble magnetic ceramics, we demonstrate the fabrication of textured alumina in details. The susceptibility of diamagnetic $\alpha$-alumina is very small, but the orientation energy of the alumina particle by a high magnetic field becomes greater than the thermal energy. $\alpha$-Alumina with a rhombohedral structure shows anisotropic susceptibility, but this anisotropy has up to now been more or less ignored due to its very low value. However, in a high magnetic field, the energy of crystal anisotropy becomes comparable to or greater than the energy of thermal motion. The degree of orientation depends on the processing factors, such as heating temperature, particle size, applied magnetic field, concentration of the suspension, etc. This process technique confers several advantages and it is possible for this type of processing to be applied to other non-cubic ceramics, such as $\mathrm{TiO}_{2}, \mathrm{ZnO}$, SnO, hydrooxy apatite (HAP), AlN, SiC, $\mathbf{S i}_{3} \mathbf{N}_{4}$, etc. [Received September 15, 2004; Accepted October 26, 2004]
\end{abstract}

Key-words : Textured ceramics, Alumina, Colloidal processing, Magnetic field, Degree of orientation

1. Introduction

$\mathbf{T}$ HE controlled development of texture is one of the ways for effectively improving physical and mechanical properties. ${ }^{1)}$ Textured ceramics have been produced by a variety of techniques; such as tape casting, ${ }^{2}$ hot forging or pressing, ${ }^{3,4)}$ and templated or seeded grain growth..$^{5)}$-7) Ceramic platelets, fibers or whiskers are used as seeded particles along with some additives to promote the anisotropic grain growth during sintering. ${ }^{5)}$ Alumina is commonly used due to its good mechanical and thermal conductivity, optical properties, etc. Therefore, many studies have been carried out on the production of textured alumina. ${ }^{8), 9)} \alpha$-Alumina with a rhombohedral structure shows an anisotropic susceptibility, but this anisotropy has up to now been more or less ignored due to its very low value. ${ }^{10)}$ However, the development of the superconducting magnet is extending the potential applications of strong magnetic fields. ${ }^{11)-16)}$

Liquid-helium free superconducting magnets are now on the market, mostly manufactured by Japanese companies, with various types, such as the large bore type $(45 \mathrm{~cm}$ at $3.5 \mathrm{~T})$, the rotate bore type, the split type, the high magnetic field type $(52 \mathrm{~mm}$ in diameter at $15 \mathrm{~T})$, etc. ${ }^{15), 16)}$ These magnets are used not only in academia but also in industries for material (mainly polymer) processing purposes. High magnetic fields provided by these superconducting magnets have made it possible to visualize the magnetic effects on feeble magnetic materials such as diamagnetic and paramagnetic materials, on which a magnetic field has been considered to reveal negligible effects. These effects are based on the magnetization force, which is classified into two types. One is by which ferromagnetic and paramagnetic materials are pulled to a magnet and diamagnetic materials are repulsed and the other is by which materials are rotated in the applied magnetic direction. ${ }^{15)}{ }^{16)}$ The former force has been mainly used for magnetic separation, ${ }^{17)}$ mag- netic levitation ${ }^{11)}$ and the measurement of the magnetic susceptibility of materials. ${ }^{17), 18)}$ The latter is used for the alignments of crystal orientation and texture structures on the basis of the magnetic susceptibility difference due to the crystal magnetic anisotropy and the demagnetization factor difference due to the shape anisotropy. The possibility of magnetic transportation and magnetic rotation was then examined under several processes such as solidification, ${ }^{13), 19)}$ electro-deposition, ${ }^{20)}$ vapor-deposition ${ }^{21)}{ }^{22)}$ and solid phase reaction. ${ }^{23)}$

In this review paper, we demonstrate that the highly textured microstructure of dense alumina can be fabricated by colloidal processing under a strong magnetic field, followed by heating, ${ }^{24)-27)}$ and that this process is used for microstructure development of the textured alumina by adding several kinds of impurities or second phases. ${ }^{28)-30)}$ Also, this process technique confers several advantages and it is possible for this type of processing to be applied to other non-cubic ceramics, such as $\mathrm{TiO}_{2}, \mathrm{ZnO}, \mathrm{SnO}, \mathrm{HAP}, \mathrm{AlN}, \mathrm{SiC}$, etc. ${ }^{31-38)}$

\section{Concept of magnetic alignment of feeble magnetic ceramics ${ }^{16)}$}

A crystal with an anisotropic magnetic susceptibility will rotate to an angle minimizing the system energy when placed in a magnetic field. The reduction of the magnetic energy on the rotation is expressed by the following equation,

$$
\Delta E=-\Delta \chi V B^{2} / 2 \mu_{0}
$$

where $\Delta \chi=\chi_{\mathrm{a}, \mathrm{b}}-\chi_{\mathrm{c}}$ is the anisotropy of the magnetic susceptibility, $\mu_{0}$ the permeability in a vacuum, $B$ is the applied magnetic field and $V$ is the volume of each particle. A macroscopic alignment could occur when $\Delta E$ exceeds the thermal energy $k_{\mathrm{B}}$ $T$. This condition is expressed as

$$
V>2 k_{\mathrm{B}} T \mu_{0} /|\Delta \chi| B^{2}
$$




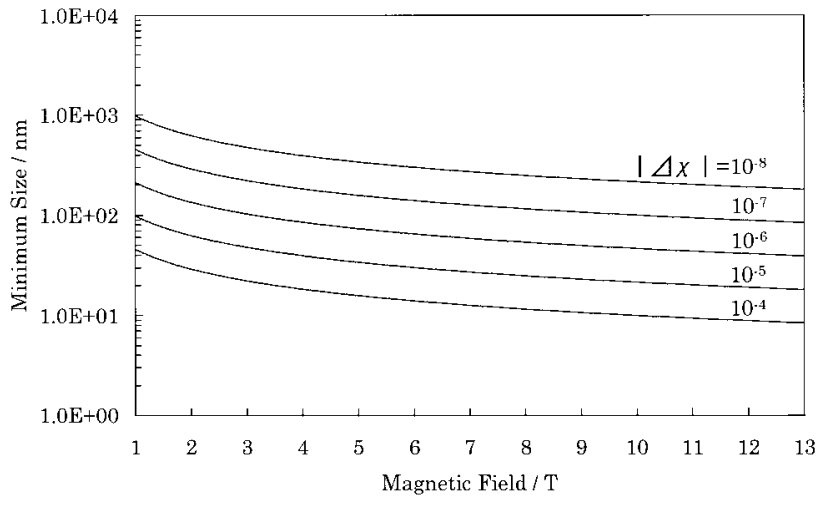

Fig. 1. Minimum particle size necessary to exceed the thermal energy at $300 \mathrm{~K}$ for various anisotropy of the magnetic susceptibility.

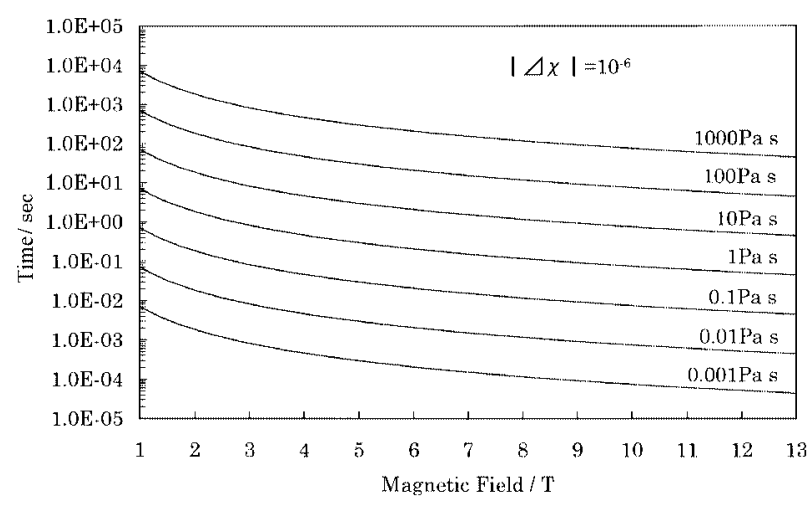

Fig. 2. Time required for the magnetic alignment of a particle suspended in a liquid with various viscosities for a fixed anisotropy of the magnetic susceptibility of $10^{-6}$.

From this equation, we can estimate the minimum critical volume, i.e., particle size, necessary for the alignment as a function of the applied magnetic field and the anisotropy of the magnetic susceptibility. These results are shown in Fig. 1.

The torque $\mathrm{N}$ acting on the particle is expressed as ${ }^{16)}$

$$
N=V \Delta \chi B^{2} \sin \zeta \cos \zeta \omega / \mu_{0},
$$

where $\omega$ is the unit vector normal to particle axis $\boldsymbol{n}$ and the magnetic flux axis $\boldsymbol{B}$, and $\zeta$ is the angle between $\boldsymbol{n}$ and $\boldsymbol{B}$. If a particle is immersed in a viscous liquid with viscosity $\eta$, the particle rotation is governed by the balance of the magnetic torque and the hydrodynamic torque. The solution is given by ${ }^{16)}$

$$
\tan \zeta=\tan \zeta_{0} \exp (-t / \tau),
$$

with the alignment rate $\tau^{-1}$ being defined as

$$
\tau^{-1}=(V / L) \Delta \chi B^{2} / \mu_{0}
$$

For a sphere of radius $r$, since the hydrodynamic term $L=$ $8 \pi \eta r^{3}$ and $V=(4 / 3) \pi r^{3}$, we obtain ${ }^{16)}$

$$
\tau^{-1}=\Delta \chi B^{2} / 6 \eta \mu_{0} .
$$

It should be noted that the alignment rate does not depend on the volume of the particle. In Fig. 2, $\tau$ is plotted as a function of the magnetic field for various values of viscosity. Based on the above considerations, the conditions necessary for the magnetic alignment to occur are as follows: the size of the particle is large enough to overcome the thermal motion and

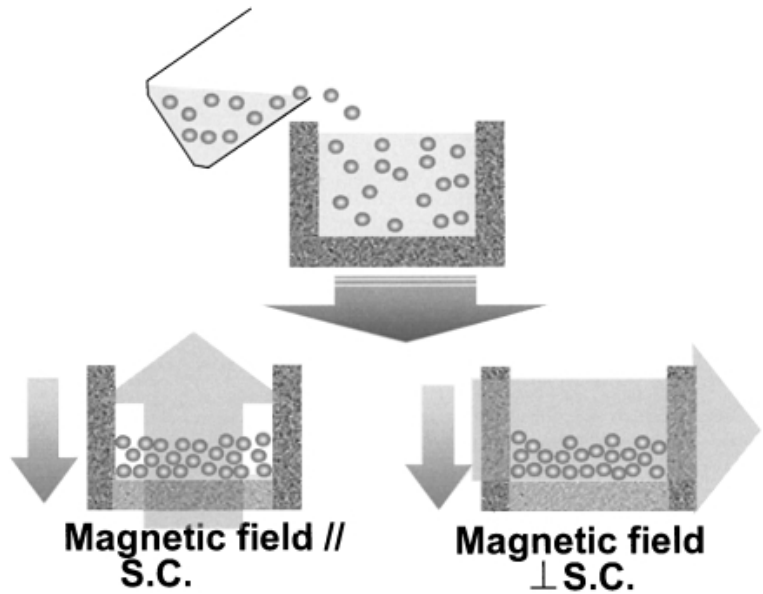

Fig. 3. Schematic of slip casting under magnetic field.

the viscosity of the surrounding medium should be low. The colloidal dispersion of ceramic particles is one of the suitable conditions for particle alignment.

\section{Experimental procedure}

The dispersion of powder in a suspension is necessary for the effective utilization of the magnetic field, because a strong interaction between the agglomerated particles in a suspension prevents each particle in the suspension from rotating during application of the magnetic field. Colloidal processing has been used in this study because its processing is very effective in developing consolidated fine particles, thereby avoiding heterogeneous agglomerates, by using repulsive surface forces. ${ }^{39), 40)}$

In the colloidal processing such as slip casting, the most important point is to obtain a well-dispersed suspension. In our experiments, an appropriate amount of ammonium polycarboxylate was added to improve the colloidal stability by electrosteric repulsion. ${ }^{40)-43)}$ It is well-known that appropriate amount of addition of polyelectrolyte exists and re-coagulation occurs if the addition of polyelectrolyte exceeds the isotherm adsorption amount. Here, redispersion treatment of powders is necessary because fine particles tend to agglomerate due to van der Waals attraction. We have shown that ultrasonication effectively disperses fine particles such as $\mathrm{Al}_{2} \mathrm{O}_{3}{ }^{44)}$,45) The rheological behavior of the suspensions was examined for estimating the colloidal stability.

A magnetic field in the range of $0-10 \mathrm{~T}$ was applied to the suspension during slip casting. The direction of the magnetic field was parallel and perpendicular to the direction of the casting direction as schematically shown in Fig. 3. In comparison, slip casting was conducted without a magnetic field. It is noted in this process that the magnetic field is only applied during colloidal processing (slip casting) and that sintering is normal heating without magnetic field.

\section{Fabrication of textured ceramics by slip casting in a high magnetic field}

\subsection{Alumina}

High-purity (>99.99\%) spherical $\alpha$-alumina particles with a mean particle size of $0.20 \mu \mathrm{m}$ were used. The particles are spherical and non-agglomerated single crystal. Using the reported value of $\Delta \chi,{ }^{10), 46)}$ the particle size of $0.20 \mu \mathrm{m}$ and $B$ $=10 \mathrm{~T}, \Delta E$ calculated by Eq. (1) is greater than the energy of thermal motion at $T=300 \mathrm{~K}$. 

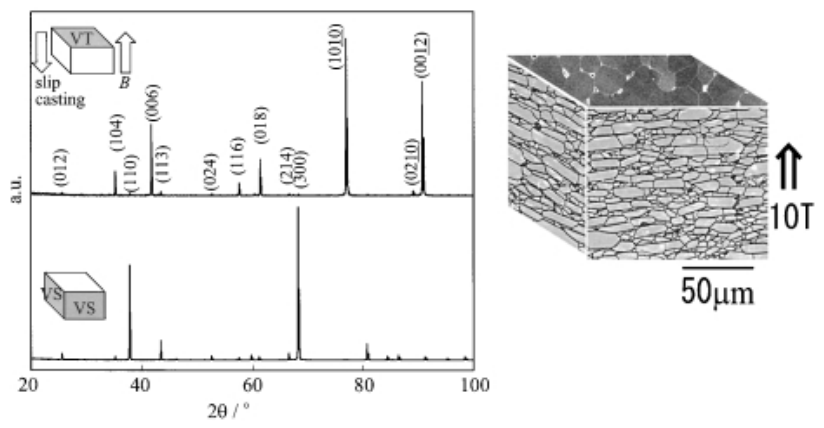

Fig. 4. X-ray diffraction patterns and SEM micrograph of alumina sintered at $1873 \mathrm{~K}$, where the direction of the magnetic field was parallel to the fluid.
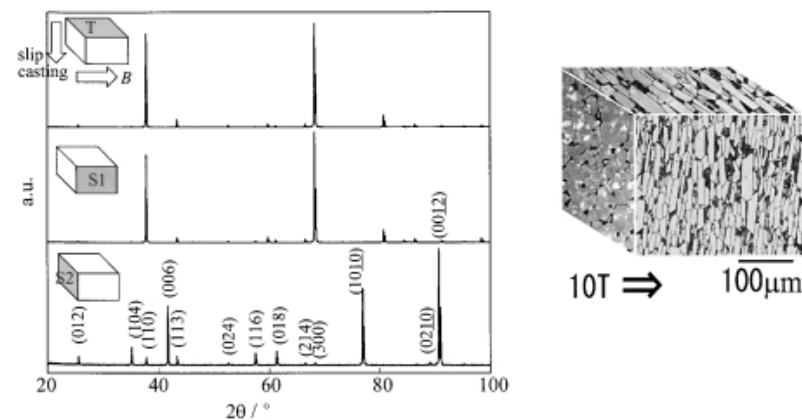

$10 \mathrm{~T} \Rightarrow$

Fig. 5. X-ray diffraction patterns and SEM micrograph of alumina sintered at $1873 \mathrm{~K}$, where the direction of the magnetic field was perpendicular to the fluid.

Figure 4 shows the XRD profiles and SEM image of the specimen which was compacted by slip casting of a $40 \mathrm{vol} \%$ solids suspension of alumina in $10 \mathrm{~T}$, followed by sintering at $1873 \mathrm{~K}$ for $2 \mathrm{~h}^{24), 25)}$ The direction of the magnetic field was parallel to the casting direction. For the surface perpendicular to the magnetic field (VT), the intensities of the $(00 l)$ peaks are very high. In contrast, for the surface parallel to the magnetic field (VS), the intensities of the $(h k 0)$ peaks are very high. This demonstrates that a crystalline texture with the $c$ axis parallel to the magnetic field has been developed by slip casting in a strong magnetic field followed by heating. For the sample slip-casted without a magnetic field, slightly plate-like grains appeared randomly distributed in the untextured material. Figure 5 shows the XRD profiles and SEM image of the sintered specimen when the direction of the magnetic field was perpendicular to the casting direction. For the surface perpendicular to the magnetic field (S2), the intensities of the (006) peak are very high. In contrast, for the surface parallel to the magnetic field ( $\mathrm{T}$ and $\mathrm{S} 1)$, the intensities of the $(h k 0)$ peaks are very high. It is also confirmed that the platelet grains are aligned perpendicular to the magnetic field after heating.

Figure 6 shows the degree of crystalline texture together with the densities and the grain sizes as a function of the heating temperature for the specimens prepared by slip casting of the $40 \mathrm{vol} \%$ solids suspension in $10 \mathrm{~T}$ ( $\mathrm{H} / /$ the fluid flow) and the specimens prepared without applying a magnetic field. ${ }^{24)}$ The degree of crystalline texture $\left(P_{1}\right)$ was determined using the following equation,

$$
P_{1}=I_{006} /\left(I_{006}+I_{110}\right)
$$

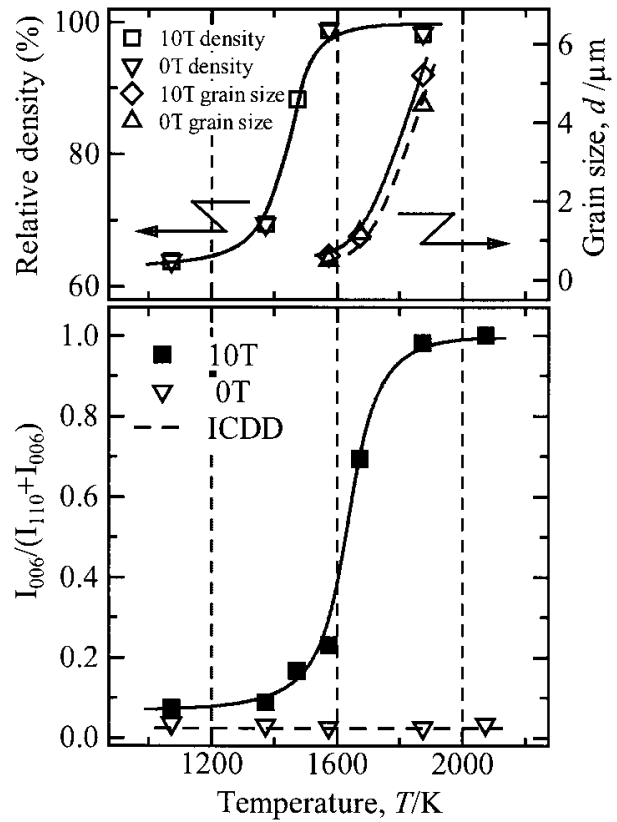

Fig. 6. Effect of temperature on degree of orientation, grain size and density.

where $I_{006}$ and $I_{110}$ are the X-ray diffraction intensities from the 006 and the 100 reflections on the surface perpendicular to the magnetic field, respectively. For those specimens not exposed to a magnetic field, the degree of crystalline texture is approximate 0.025 . As a comparison, in the specimens exposed to a strong magnetic field, the degree of crystalline orientation up to $1373 \mathrm{~K}$ was small, but it should be noted that this value is slightly greater than that of the untextured material. The degree of orientation appeared to rapidly increase at temperatures above $1573 \mathrm{~K}$ where large grain growth was observed. It is clear that crystallographic texture development accompanies the grain growth.

Here, the evaluation of the texture by XRD using Eq. (7) is not sufficient especially for the green bodies. Development of texture evaluation technique has been required for evaluation the texture quality. Polarized light micrograph technique developed by Uematsu et al. is a useful method for evaluating the texture of green bodies. ${ }^{47), 48)}$ According to their analysis, ${ }^{47)}$ the degree of orientation of the green bodies is much greater than that estimated by Eq. (7). To evaluate the texture quality, the orientation distributions of the $\alpha-\mathrm{Al}_{2} \mathrm{O}_{3}$ textured ceramics were determined from a neutron diffraction analysis. ${ }^{49)}$ Curved position-sensitive detectors and 4-circle diffractometry allow the entire diffraction pattern treatment in the combined Rietveld-WIMV-Popa algorithm. Figure 7 shows the inverse pole figures calculated for the $c$-axis direction (parallel to the magnetic field) that show a major (001) component for four textured alumina ceramics prepared by slipcasting in $10 \mathrm{~T}$ and then sintered at $1073 \mathrm{~K}, 1573 \mathrm{~K}, 1673 \mathrm{~K}$ and $1873 \mathrm{~K}^{49)}$ The inverse pole figure represents the texture contrary to the pole figure which only represents the distribution of one crystallographic plane for many sample orientations. The density (multiple of random distribution: m.r.d) is a normalization of the diffracted intensity onto the entire diffracted intensity of the sample for many possible sample orientations; as an example, a powder with no preferential orientation has a density equal to 1 m.r.d and a higher density indicates a high orientation. It is clearly seen that the density 

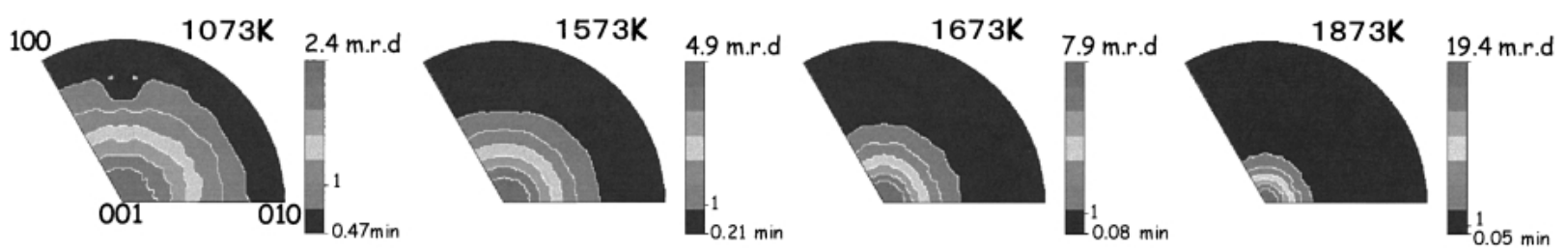

Fig. 7. Inverse pole figures calculated $z$ fiber direction (parallel to the magnetic field) for sampled sintered at (a) $1073 \mathrm{~K}$, (b) $1573 \mathrm{~K}$, (c) $1673 \mathrm{~K}$ and (d) $1873 \mathrm{~K}$.

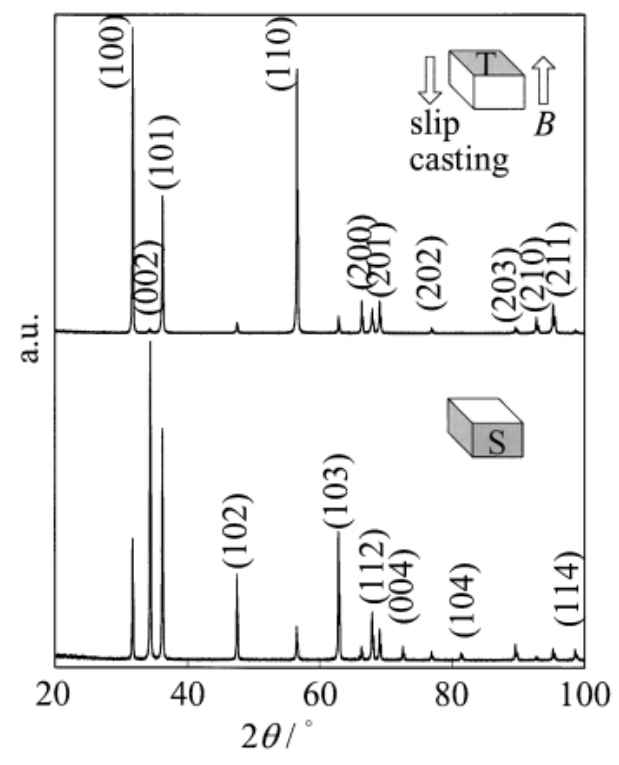

Fig. 8. X-ray diffraction patterns of $\mathrm{ZnO}$ sintered at $1673 \mathrm{~K}$ in the planes perpendicular and parallel to the applied magnetic field, which is parallel to the casting direction.

of 001 at $1073 \mathrm{~K}$ (Fig. 7 (a)) is not so large and scattered. Increasing with the sintering temperature, however, the texture strength is enhanced and the $c$-axis distribution becomes narrower.

\section{$4.2 \mathrm{ZnO}^{33)}$}

The particles used were spheroid with a $50 \mathrm{~nm}$ length and 25 $\mathrm{nm}$ width. Figure 8 illustrates the XRD profiles of the $\mathrm{ZnO}$ which was compacted by s1ip casting in $10 \mathrm{~T}$, followed by heating at $1673 \mathrm{~K}$ for $5 \mathrm{~h}$ in air. The direction of the magnetic field was parallel to the casting direction. For the surface perpendicular to the magnetic field ( $T$ in Fig. 8), the intensities of the $h k 0$ reflections are very large. In contrast, for the surface parallel to the magnetic field ( $\mathrm{S}$ in Fig. 8), the intensity of the 001 reflections are large and the intensities of the 103 and 102 reflections at the interplanar angle of 31.7 and 42.8 with the basal plane, respectively, are also large. Therefore, it is clear that a crystalline texture with the $c$-axis perpendicular to the magnetic field is developed by slip casting in a high magnetic field followed by heating.

The degree of the crystalline orientation was estimated in terms of the Lotgering oriention factor $f$ from the $\mathrm{X}$-ray diffraction measurements. The orientation factor $f$ is defined $\mathrm{as}^{50)}$

$$
f=\left(P-P_{0}\right) /\left(1-P_{0}\right),
$$

where $P$ and $P_{0}=\Sigma I(h k 0) / \Sigma I(h k l)$ are the intensities from the $h k l$ reflection over a certain range of $2 \theta$ values on the

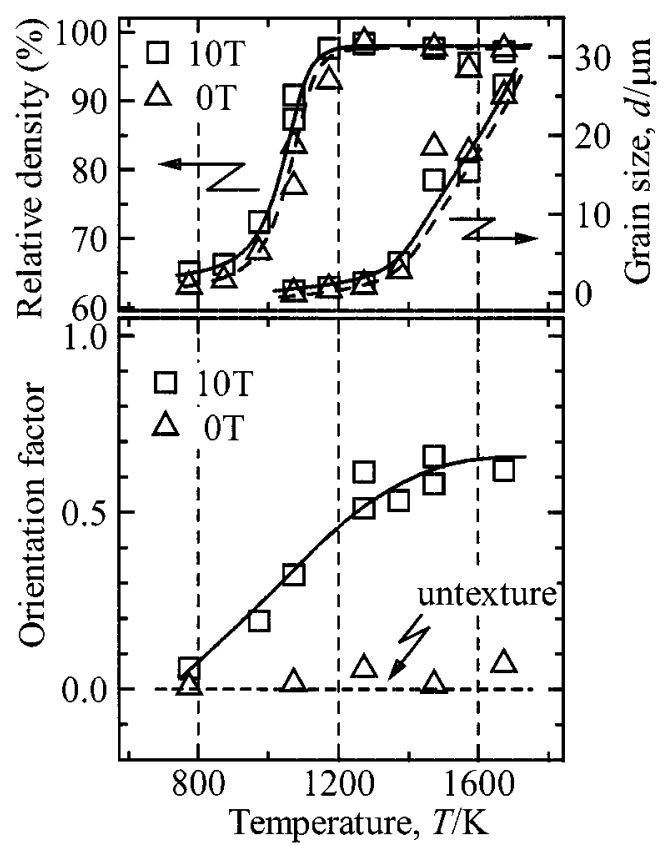

Fig. 9. Effect of temperature on the degree of crystalline texture, density band grain size in $\mathrm{ZnO}$ consolidated by slip casting in $10 \mathrm{~T}$ and without magnetic field.

surface perpendicular to the direction of the magneticfield. The values of $P$ were calculated from the ratio of the sum of the $(h k l)$ intensities to that of all the $(h k l)$ intensities for the samples prepared by this method, and the value of $P_{0}$ was calculated from the International Center for Diffraction Data (ICDD) value. For the random orientation sample, $f$ is equal to zero, and the absolute value of $f$ increases with the increasing degree of orientation. The absolute value of $f$ approaches unity for an ideally textured material. Figure 9 shows the degree of crystalline orientation together with the relative density and the grain size as a function of the heating temperature for the samples prepared by slip casting in $10 \mathrm{~T}$ (B // the casting direction) and the samples without appllying a magnetic field. The trend is similar to those of the alumina sample; the degree of texture increases with the increasing temperature.

4.3 Titania $^{31)}$

Fine spherical $\mathrm{TiO}_{2}$ (mainly anatase-type structure) powder with particles averaging $30 \mathrm{~nm}$ in size was dispersed in water and suspensions with 20 vol\% solids were prepared. Figure 10 shows the X-ray diffraction profiles of $\mathrm{TiO}_{2}$ which was slip casted in $10 \mathrm{~T}$ and sintered at $1573 \mathrm{~K}$ for $2 \mathrm{~h}$ in air. We have confirmed by XRD that heating at $1273 \mathrm{~K}$ fully transforms the anatase into rutile crystals. For the surface perpendicular to the magnetic field, ( $\mathrm{T}$ in Fig. 10), the intensity of the 002 reflection is very large and that of the 101 reflection at the 


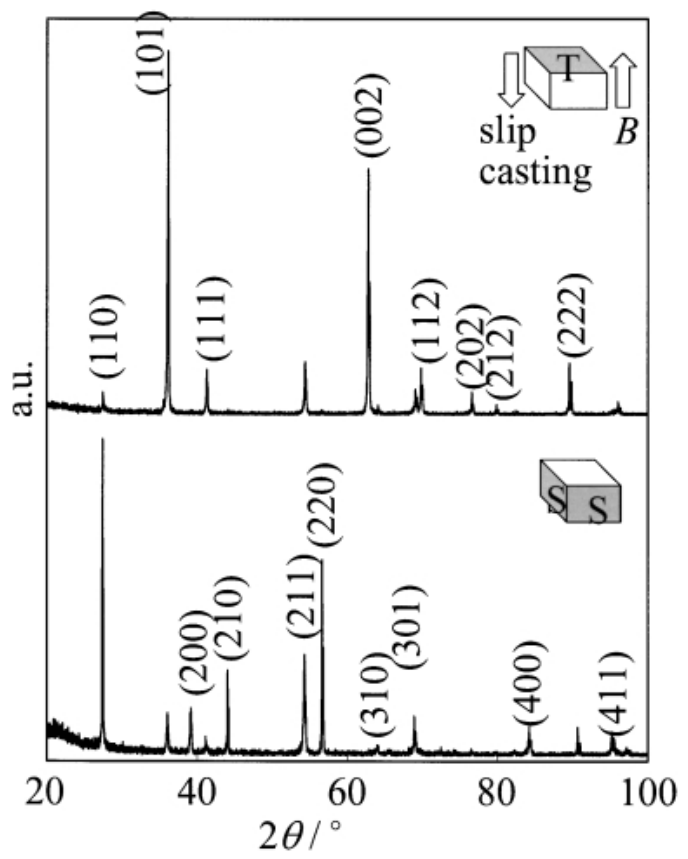

Fig. 10. X-ray diffraction patterns of titania sintered at $1573 \mathrm{~K}$ in the planes perpendicular and parallel to the applied magnetic field, which is parallel to the casting direction.

interplanar angle of 32.8 with the basal plane is also large. In contrast, for the sample parallel to the magnetic field $(\mathrm{S}$ in Fig. 10), the intensities of the $h k 0$ reflections are large. Therefore, for titania, the crystalline texture with the $c$-axis parallel to the magnetic field was developed by slipcasting in a high magnetic field and heating. Figure 11 shows the orientation factor together with the relative density and the grain size as a function of the heating temperature. The degree of crystalline texture was determined using Eq. (9) from the intensities of the X-ray diffraction measurement.

$$
P=\frac{I_{002}}{I_{002}+I_{110}}
$$

where $I_{002}$ and $I_{110}$ are the intensities from the 002 and the 110 reflections, respectively, on the surface perpendicular to the direction of the magnetic field. This trend is also similar to those of alumina.

Figure 12 shows the microstructures of the polished sections of the specimen not subjected to a magnetic field and the specimen prepared by slip casting at $10 \mathrm{~T}$ (B// the casting direction), followed by sintering at $1273 \mathrm{~K}$ and $1673 \mathrm{~K}$. It can be seen that equiaxed grains appear randomly distributed in the untextured material prepared without exposure to a magnetic field (Figs. 12(a) and 12(c)). For the specimens prepared by slip casting in $10 \mathrm{~T}$, equiaxed grains were observed in the specimen sintered at $1273 \mathrm{~K}$ (Fig. 12(b)) where the degree of crystalline texture was small. By comparison, the slightly elongating grains are aligned parallel to the magnetic field and the aspect ratio of these grains was 1.5 in Fig. 12(d) where the crystalline texture was extremely high.

4.4 Summary of ceramics published

Table 1 summarizes the reported textured ceramics with a feeble magnetic susceptibility fabricated by slip casting in a magnetic field together with our unreported ones. Except for $\alpha$-alumina, ${ }^{10)}$ the values of $\chi_{\mathrm{c}}$ and $\chi_{\mathrm{a}, \mathrm{b}}$ are not reported but we can estimate which is larger by the texture development due to

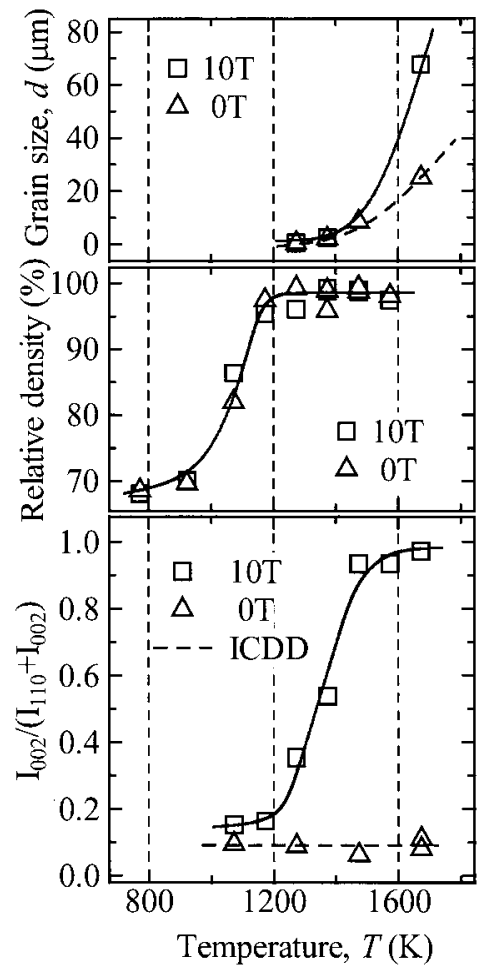

Fig. 11. Effect of temperature on the degree of crystalline texture, density band grain size in titania consolidated by slip casting in $10 \mathrm{~T}$ and without magnetic field.

the applied magnetic field.

When $\chi_{\mathrm{c}}$ is larger than $\chi_{\mathrm{a}, \mathrm{b}}$, the $c$-axis of the crystal is only the preferred direction the parallel to the applied magnetic field direction. On the other hand, when $\chi_{\mathrm{c}}$ is smaller than $\chi_{\mathrm{a}, \mathrm{b}}, a$ - or $b$-axis of the crystal is the preferred direction parallel to the applied magnetic field direction. This situation means that the $c$-axis of a particle can align in all of the directions perpendicular to the applied magnetic field; therefore, the crystal orientation can not be determined in one direction by simple slip casting under magnetic field. In this case, a special technique is necessary; applying a magnetic field rotating on the $a-b$ plane to a suspension is one solution, where the $c$ axis of particles can align to the casting direction. ${ }^{16)}$

\section{Process factors and microstructure control}

The alignment of particle is considered to be strongly dependent on the degree of dispersion. Figure 13 shows effect of dispersion state on the degree of orientation of alumina prepare by slip casting in $10 \mathrm{~T}$ and sintering at $1873 \mathrm{~K}$, where each suspension was prepared by different amounts of dispersant. It is cleary seen that the sample prepared by well-dispersed with low-viscosity showed greater textured orientation. Next, to clarify the effect of solids contents on crystalline texture, three kinds of alumina suspensions varying the solids contents of 30,40 and 45 vol\% were prepared. Figure 14 shows the effect of solids content of alumina and applied magnetic field on the degree of crystalline orientation after heating at $1873 \mathrm{~K}$ for $2 \mathrm{~h}$. The degree of orientation rapidly increased at a certain magnetic field as is expected by Eq (1). However, it is noted that the degree of orientation is strongly dependent on the solids content. This phenomenon is not explained only by the Eq. (1). It is seen that the solids content, i.e., viscosity of the suspension, must be low as each particle can easily rotate in 

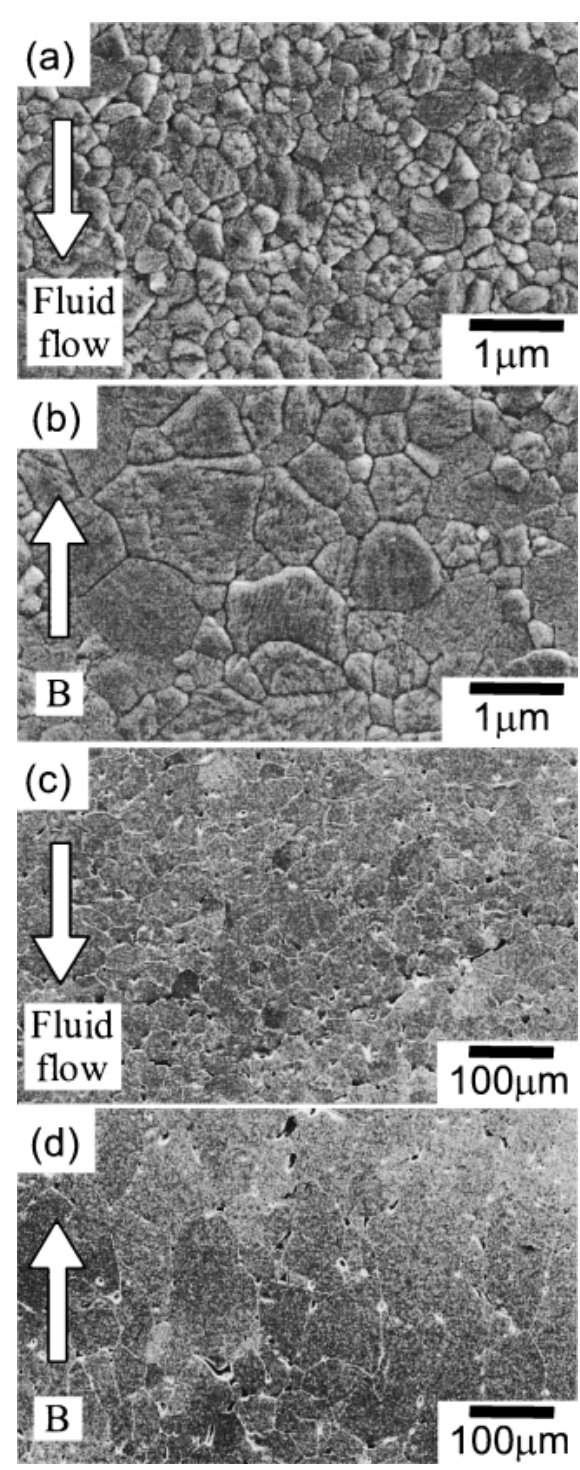

Fig. 12. Microstructures of titania sintered at $1273 \mathrm{~K}$ and $1673 \mathrm{~K}$. (a) and (c) are prepared by slip casting without a magnetic field. (b) and (d) are prepared by slip casting in a magnetic field $(10 \mathrm{~T})$. (a) and (b) are the specimens sintered at $1273 \mathrm{~K}$, (c) and (d) are the specimens sintered at $1673 \mathrm{~K}$.

Table 1. Reported Textured Feeble Magnetic Ceramics Prepared by Colloidal Processing in a High Magnetic Field

\begin{tabular}{|c|c|c|c|}
\hline Materials & Crystal structure & $\begin{array}{l}\text { Difference of } \\
\text { magnetic } \\
\text { susceptibility }\end{array}$ & Reference \\
\hline$\alpha-\mathrm{Al}_{2} \mathrm{O}_{3}$ & rhombohedral & $x_{c}>x_{a, b}$ & 24), 25) \\
\hline $\mathrm{TiO}_{2}$ & tetragonal & $x_{\mathrm{c}}>x_{\mathrm{a}, \mathrm{b}}$ & 31) \\
\hline $\mathrm{ZnO}$ & hexagonal & $x_{c}<x_{i, b}$ & 33) \\
\hline hydroxyapatite & hexagonal & $x_{\mathrm{c}}<x_{\mathrm{a}, \mathrm{b}}$ & 34),38) \\
\hline $\mathrm{Si}_{3} \mathrm{~N}_{4}$ & hexagonal & $x_{c}<x_{a, b}$ & 37) \\
\hline AlN & hexagonal & $x_{c}<x_{\mathrm{a}, \mathrm{b}}$ & 38) \\
\hline $\mathrm{SiC}$ & hexagonal & $x_{c}>x_{\mathrm{a}, \mathrm{b}}$ & $38)$ \\
\hline $\mathrm{SnO}_{2}$ & tetragonal & $x_{\mathrm{c}}>x_{\mathrm{a}, \mathrm{b}}$ & 38) \\
\hline Bismuth titanate & orthorhombic & $x_{\mathrm{c}}<\chi_{\mathrm{a}, \mathrm{b}}$ & $36), 38)$ \\
\hline
\end{tabular}

strong magnetic fields.

Figure 15 shows the effect of the particle sizes and heating temperatures on the degree of orientation for three kinds of alumina prepared by the slip casting of a $30 \mathrm{vol} \%$ solids suspension in $10 \mathrm{~T}$. The degree of orientation after slip casting
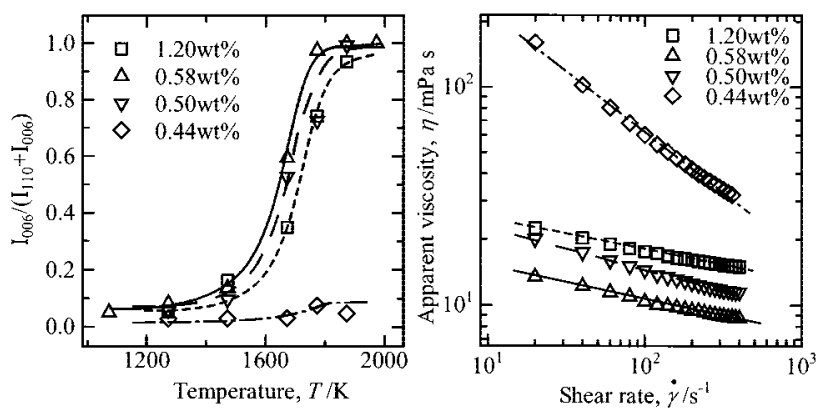

Fig. 13. Effect of dispersant amounts in suspension on the degree of orientation after heating at $1873 \mathrm{~K}$ for $2 \mathrm{~h}$ for four kinds of alumina prepared by slip casting of $30 \mathrm{vol} \%$ solids suspension in $10 \mathrm{~T}$, and apparent viscosity of dispersant amounts in suspension.
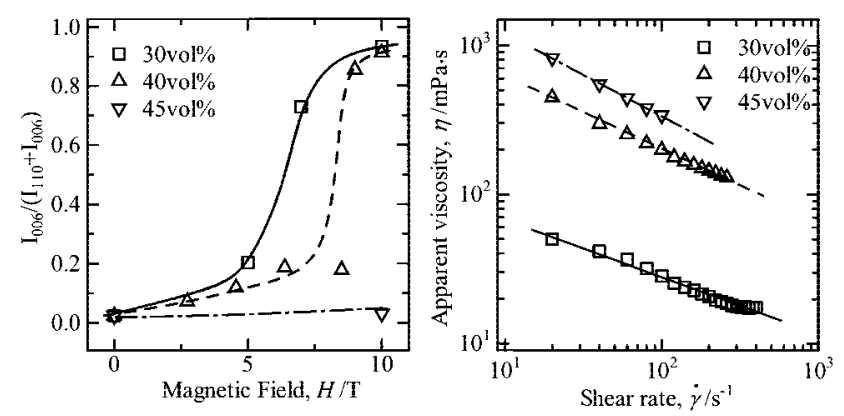

Fig. 14. Effect of solids volume in suspensions and an applied magnetic field on the degree of orientation after heating at $1873 \mathrm{~K}$ for $2 \mathrm{~h}$, and apparent viscosity solids volume in suspensions.

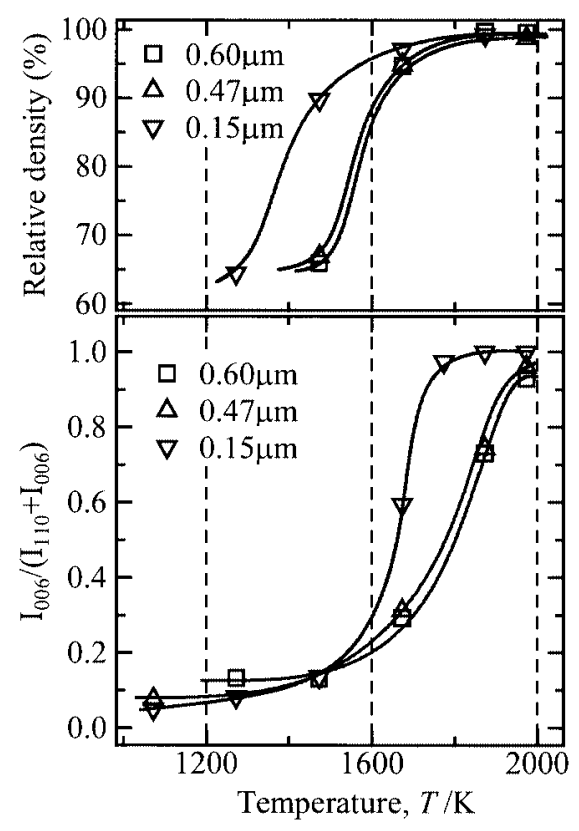

Fig. 15. Effect of particle sizes and heating temperatures on the degree of orientation for three kinds of alumina prepared by slip casting of $30 \mathrm{vol} \%$ solids suspension in $10 \mathrm{~T}$.

and heating at low temperatures depends on the particle size. At lower heating temperatures, the degree of orientation of the large particles is greater than that of the small particles, 


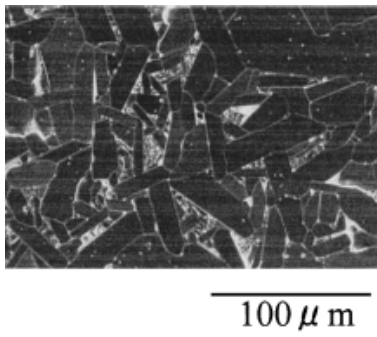

Slip cast without magnetic field
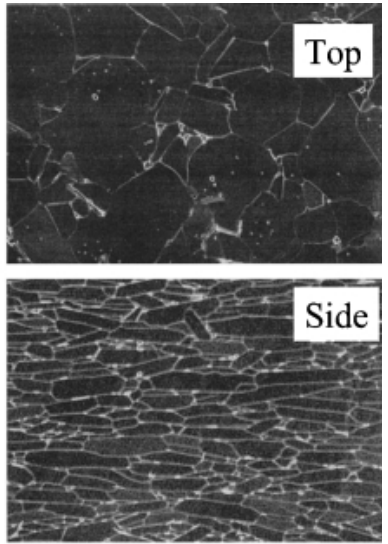

Slip casting under $10 \mathrm{~T}$

Fig. 16. SEM micrograph of sintered alumina co-doped by 0.05 $\mathrm{wt} \% \mathrm{TiO}_{2}$ and $0.05 \mathrm{wt} \% \mathrm{SiO}_{2}$. Slip casted without magnetic field (left figure) and slip casted under $10 \mathrm{~T}$, where magnetic field is perpendicular to the plane (Top: right figure), and parallel to the plane (Side: right figure).

but the difference is not as large as expected by Eq. (1). This indicates that each single particle is not completely isolated, and that the interaction among the particles prevents particle alignment in the suspension. At higher temperatures, the degree of orientation of the small particles became greater than that of the larger particles. This is due to the fact that the degree of orientation is increased with grain growth and the grain growth of small particles is greater than that of the larger particles.

The requirements for obtaining textured ceramics by slip casting in a high magnetic field and sintering are summarized as follows: (1) fine particle with single crystal and monodispersed in liquid, (2) anisotropy of magnetic susceptibility, usually non-cubic crystal structure, (3) anisotropy magnetic energy is greater than the thermal motion energy, (4) low viscosity for rotation of particle, and (5) grain-growth for highly textured ceramics. In general, non-cubic materials have anisotropic susceptibilities attributable to the ansymmetry. It was possible for this type of processing (slip casting in a strong magnetic field, followed by heating) to be applied to other non-cubic ceramics. This type of processing can be used for the production of textured ceramics with complex shapes by near-net-shape slip casting. This processing technique of fabricating the textured ceramics can be applied to other noncubic ceramics such as is shown in Table 1.

To control the alumina microstructure, doping an impurity into the alumina was conducted. It is well known that the co-doping of small amounts of $\mathrm{TiO}_{2}$ and $\mathrm{SiO}_{2}$ results in highly anisotropic abnormally grains due to the ternary eutectic liquid phase. ${ }^{51)}$ On the other hand, the co-doping of small amounts of $\mathrm{MgO}$ and $\mathrm{Y}_{2} \mathrm{O}_{3}$ depress the grain growth of alumina resulting transparent alumina. ${ }^{52)}$ In both cases, the slip casting in $10 \mathrm{~T}$ was conducted and sintered at $1873 \mathrm{~K}$ in air. The oriented factor calculated using Eq. (7) of both samples was nearly $1 .^{53)}$ Figure 16 shows SEM micrographs of the sintered alumina co-doped by $0.05 \mathrm{wt} \% \quad \mathrm{TiO}_{2}$ and $0.05 \mathrm{wt} \%$ $\mathrm{SiO}_{2}$. The highly textured structure of the elongated alumina was seen when slip cast in $10 \mathrm{~T}$. Figure 17 shows SEM micrographs of the sintered alumina co-doped by $0.05 \mathrm{wt} \% \mathrm{MgO}$ and $0.05 \mathrm{wt} \% \mathrm{Y}_{2} \mathrm{O}_{3}$, in which a fine grained microstructure was obtained.
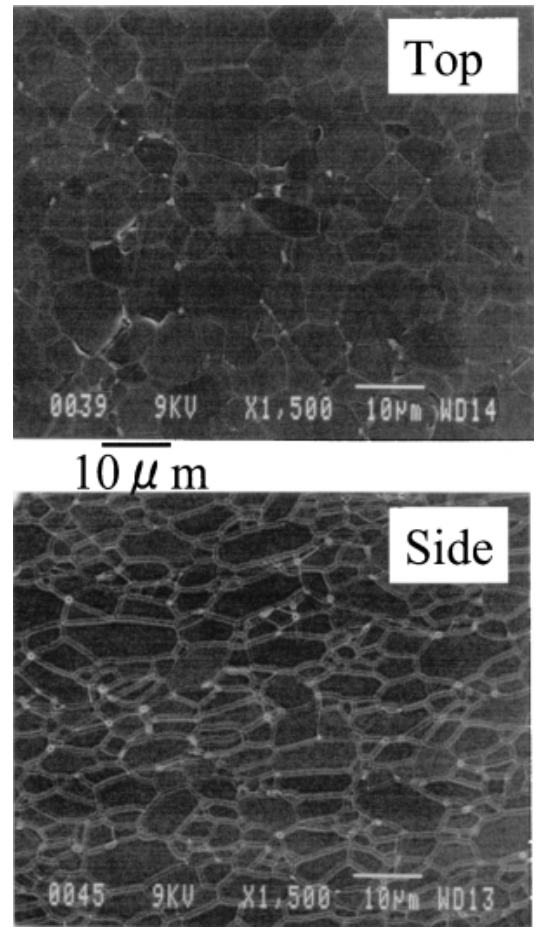

Fig. 17. SEM micrograph of sintered alumina co-doped by 0.05 wt $\% \mathrm{MgO}$ and $0.05 \mathrm{wt} \% \mathrm{Y}_{2} \mathrm{O}_{3}$. Slip casted under $10 \mathrm{~T}$, where magnetic field is perpendicular to the plain (Top), and parallel to the plane (Side).

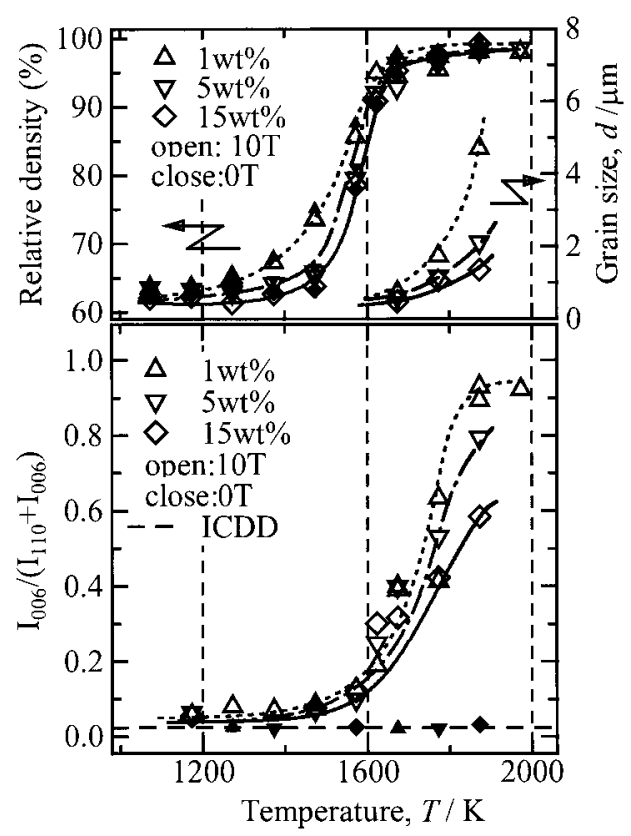

Fig. 18. Effect of temperature on the degree of crystalline texture, density and grain size of alumina for zirconia-dispersed alumina consolidated by slip casting in $10 \mathrm{~T}$ and without magnetic field.

This technique is also applied for the fabrication of the textured alumina-based composites, such as alumina-SiC, ${ }^{28)}$ and alumina-zirconia ( $3 \mathrm{~mol} \%$ yttria doped tetragonal zirconia).$^{30)}$ In both systems, the textured composites were fabricated, but the degree of texture was not so large since the grain growth of alumina was inhibited by $\mathrm{SiC}$ or zirconia as a second phase. Figure $\mathbf{1 8}$ shows the degree of crystalline texture 
of alumina determined XRD using Eq. (7) together with the densities and the grain sizes as a function of the heating temperature for zirconia-dispersed alumina. ${ }^{30)}$ The trend is similar to undoped alumina shown in Fig. 6. The grain growth of alumina decreased with the increasing the density of zirconia particles because of the pining effect of zirconia. ${ }^{54), 55)}$ The degree of crystalline orientation also decreased with the increase with the density of zirconia particles. These results show that crystallographic texture development accompanies grain growth in the specimens and zirconia particles prevent from developing crystalline orientation. Figure 19 represents the alumina grain sizes to the fourth power as a function of the isothermal annealing time at $1773 \mathrm{~K}$ in alumina containing $10 \mathrm{vol} \%$ zirconia prepared by slip casting in $10 \mathrm{~T}$ and the specimens prepared without applying a magnetic field. In Fig. $19, d_{\perp}$ and $d_{/ /}$were the average alumina grain size perpendicular and parallel to the magnetic field, respectively. The fourth power law fits the observed grain growth data and this is compatible with earlier results on 7 to $20 \mathrm{vol} \%$ zirconia-dispersed alumina. ${ }^{52), 53)}$ Therefore, the grain growth of alumina is explained by the same mechanism as "surface diffusion controlled inclusion drag" in all directions of the magnetic field. The alumina growth rate for the samples exposed to a magnetic field depends on the direction. The grain growth rate of the random

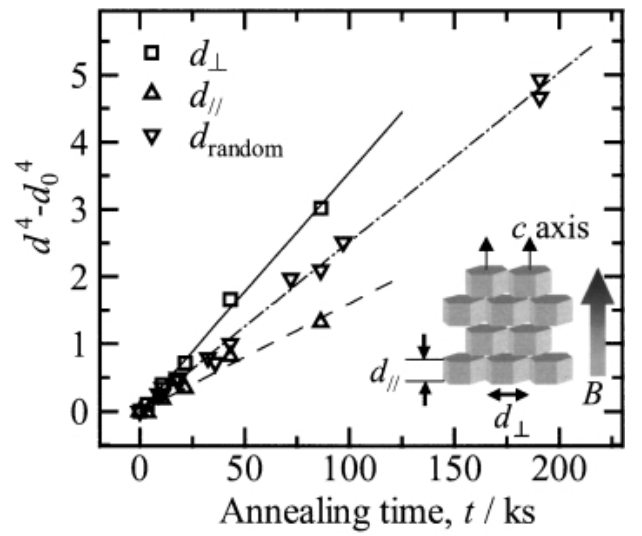

oriented specimen was between those of the directions perpendicular and parallel to the applied magnetic field.

\section{Effect of gravity ${ }^{32}$}

The particle morphology mentioned above is nearly spherical. However, when we use whisker or needle particles, special attention is necessary. As an example of such a particle, the slip casting of the titania whisker under a high magnetic field was conducted. The titania whisker has a rod-like morphology with a mean length of $1.68 \mu \mathrm{m}$ and diameter of $0.13 \mu \mathrm{m}$. The structure is a rutile-type single crystal and the long-axis is confirmed to be the $c$-axis based on its electron diffraction pattern. Aqueous suspensions containing $30 \mathrm{vol} \%$ solids of the titania whiskers were prepared and slip casting was performed. The direction of the magnetic field was parallel and perpendicular to the casting direction. In comparison, normal slip casting without a magnetic field was also conducted.

Figure 20 illustrates the XRD profiles of the specimen, which were compacted by slip casting without a magnetic field and in $10 \mathrm{~T}$, followed by heating at $1073 \mathrm{~K}$ for $2 \mathrm{~h}$. The features of the X-ray diffraction patterns of the top and the side are similar between that without the applied magnetic field (Fig. 20(a)) and that when the magnetic field was parallel to the fluid flow (B // the casting direction) (Fig. 20(b)). However, the X-ray diffraction pattern when the magnetic field was perpendicular to the casting direction ( $\mathrm{B} \perp$ the casting direction) (Fig. 20(c)) is different from the other two. To quantitatively clarify the difference, the $\mathrm{X}$-ray diffraction data were analyzed by the orientation index using the three main peaks of (110), (101) and (002). The orientation index on each cut plane was calculated based on the X-ray diffraction patterns. The orientation index of the $\left(h_{i} k_{i} l_{i}\right)$ plane $N_{h i} k_{i}$, which is defined as Eq. (10), is evaluated from the X-ray diffraction patterns as follows. ${ }^{56)}$

$$
N_{h_{i} k_{i} l_{i}}=\frac{F_{h_{i} k_{i} l_{i}}}{F_{h_{i} k_{i} l_{i}}^{0}}
$$

where $F_{h_{i} k_{l} l_{i}}$ is the intensity fraction of the $\left(h_{i} k_{i} l_{i}\right)$ plane and defined by Eq. (11), and $F_{h, k, l_{i}}^{0}$ is the standard data for the ICDD value.

Fig. 19. Relationship between the fourth power of the alumina grain size and annealing time at $1773 \mathrm{~K}$.
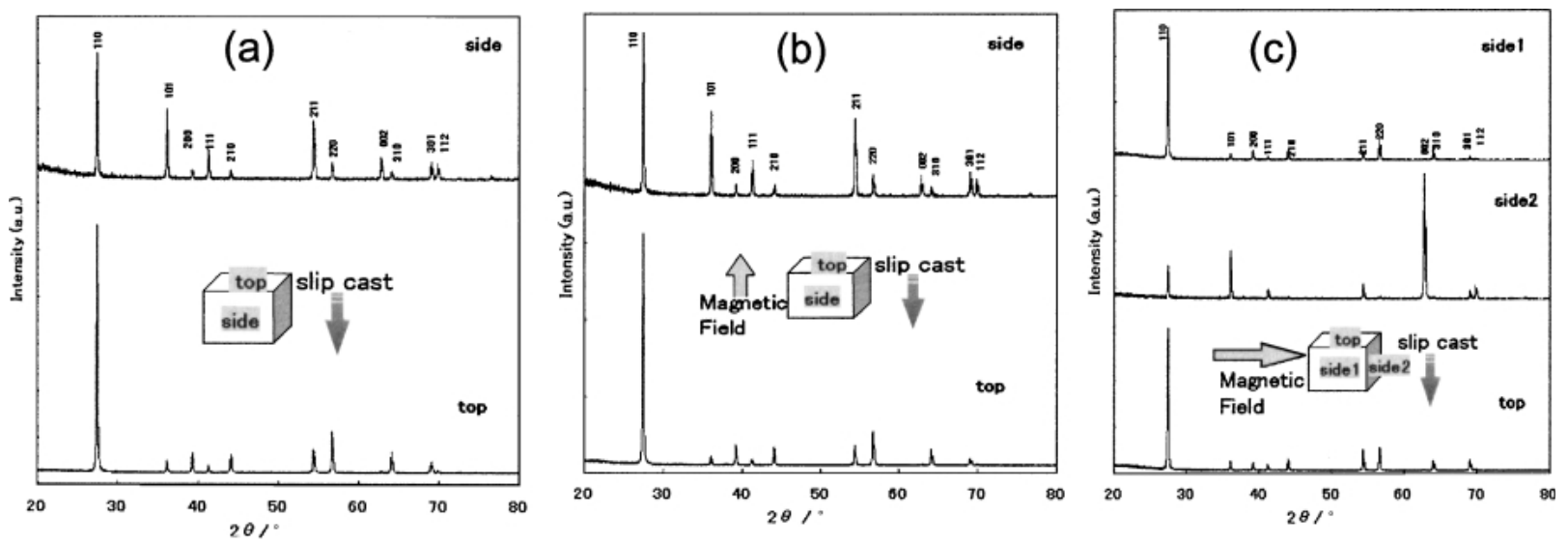

Fig. 20. X-ray diffraction patterns of the samples compacted by slip casting without a magnetic field and in $10 \mathrm{~T}$, followed by heating at $1073 \mathrm{~K}$ for $2 \mathrm{~h}$. The samples are consolidated (a) without a magnetic field, (b) in the magnetic field parallel to the fluid flow, and (c) in the magnetic field perpendicular to the fluid flow (direction of gravity). Here, the side 1 and side 2 in the samples of (a) and (b) are equivalent and both showed similar X-ray diffraction patterns; therefore in the sample of (a) an (b) only the data of side in stead of side 1 and side 2 are shown. 

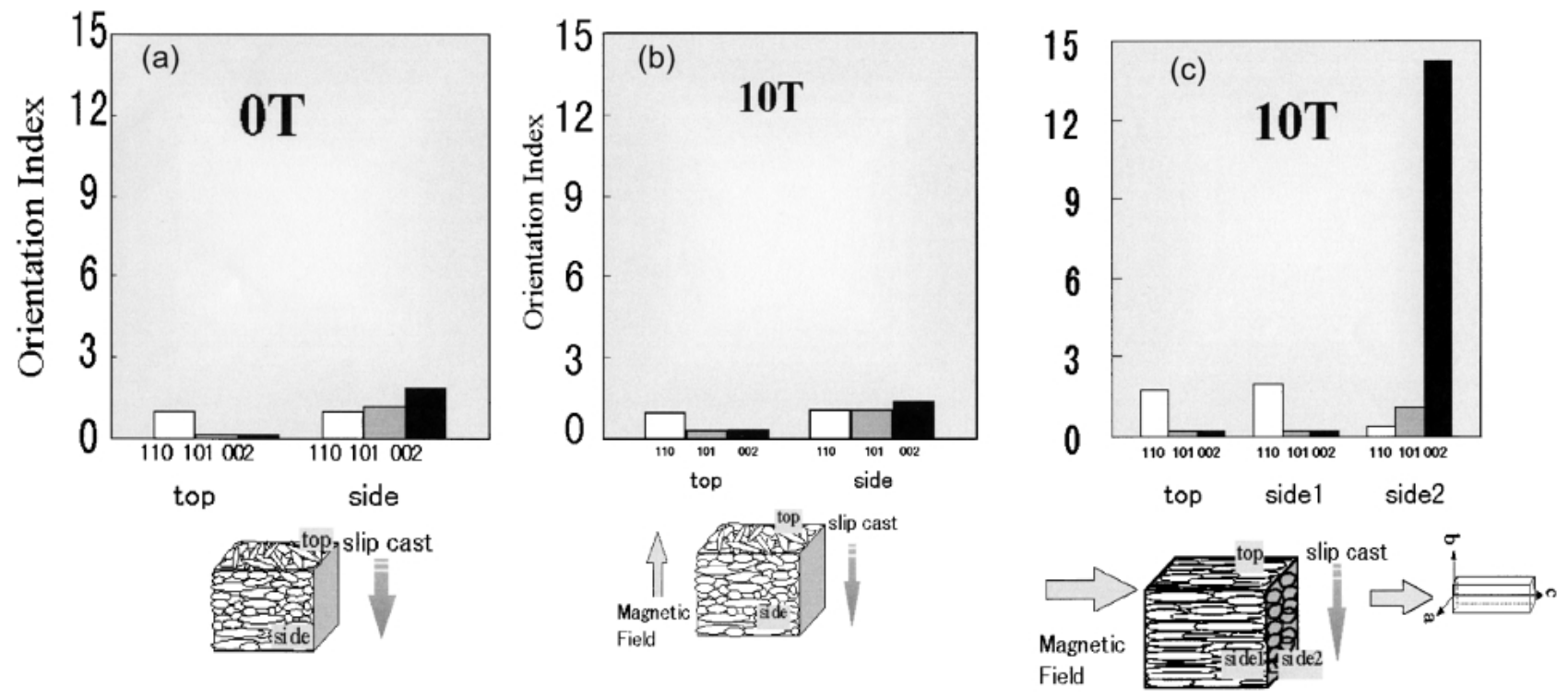

Fig. 21. Orientation indices of the peaks of (110), (101) and (002) and schematic of alignment of titania whisker. Each figure corresponds to Fig. 20.

$$
F_{h_{i} k_{i} l_{i}}=\frac{I_{h_{i} k_{i} l_{i}}}{I_{h_{1} k_{1} l_{1}}+I_{h_{2} k_{2} l_{2}}+I_{h_{3} k_{3} l_{3}}+\cdots \cdots+I_{h_{n} k_{n} l_{n}}}
$$

where $I_{h_{i} k_{i} l_{i}}$ is an intensity for the diffraction line of $\left(h_{i} k_{i} l_{i}\right)$.

For the side without a magnetic field, the intensity of the (110) peak is the same as the standard value, but the intensity of the (002) peak is higher than the standard value shown in Fig. $21(\mathrm{a})$. This means that the $c$-axis of the titania whisker is randomly distributed on the plane perpendicular to the casting direction as is schematically shown in the bottom of Fig. 21 (a). Such a weak alignment of the whisker is usually observed $^{57)}$ because the energy of gravity is predominant in the dispersed system when the particle size exceeds $0.1 \mu \mathrm{m}^{58)}$ as is the case of the present experiment. It is also seen that the intensities of both the top and the side of the samples consolidated as B // the fluid flow, is similar to those without a magnetic field (Fig. 21(b)). This phenomenon indicates that the magnetic energy is smaller than the energy of gravity.

On the other hand, from Fig. 21 (c), it is clearly seen that the sample consolidated as $\mathrm{B} \perp$ the casting direction, is affected by the magnetic field. In the planes that are parallel to the magnetic field (the top and side 1 in Fig. 21 (c)), the intensity of (110) is high while those of (101) and (002) are small. Especially, in the plane perpendicular to the magnetic field (the side 2 in Fig. 21 (c)), the intensity of (002) is very high. These results indicate that the $c$-axis of the whisker is aligned in the direction to the magnetic field on the $c$-plane as schematically shown in the bottom of Fig. 21(c). This feature is also confirmed by the SEM photographs as shown in Fig. 22.

\section{Fabrication of textured ceramics by reaction sintering ${ }^{59)}$}

For the complicated structure of multi-components, it is usually difficult to obtain a dispersed single crystal particle. In this case, reaction sintering of the textured phase and non-textured phase results in textured products. As an example we introduce the production of $\beta$-alumina, which is a $\mathrm{Na}^{+}$ionic conductor and used in the Na-S battery. ${ }^{60)}$ The ionic conductivity of this polycrystalline material is lower than that of a single crystal ${ }^{60)}$ because the polycrystalline $\beta$-alumina has conduction planes that are randomly oriented. If it is possible to

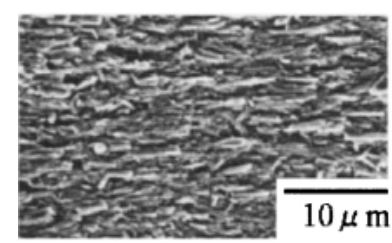

Top

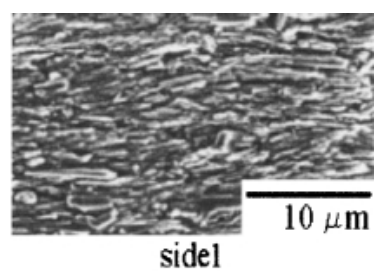

sidel

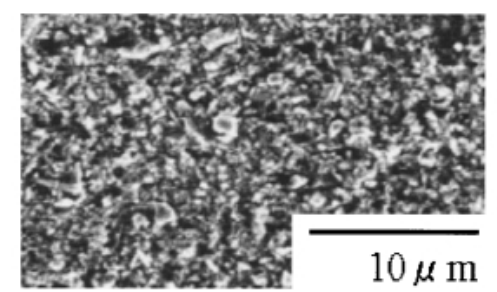

side2

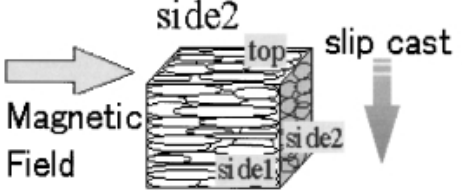

Fig. 22. SEM photographs of the top, side 1 and side 2 of the sample consolidated in the magnetic field perpendicular to the casting direction.

prepare a texture developed $\beta$-alumina polycrystalline, $\beta$-alumina with a high ion conductively is expected. To prepare the crystallite oriented $\beta$-alumina, the following reaction sintering was conducted: (1) oriented $\alpha$-alumina green bodies were prepared by colloidal processing in a high magnetic field, (2) the oriented $\alpha$-alumina green bodies were infiltrated with $\mathrm{Na}_{2} \mathrm{O}$ and $\mathrm{MgO}$, and ( 3 ) the oriented $\beta$-alumina bodies were synthesized by reaction sintering.

The textured porous $\alpha$-alumina bodies were prepared by the slip casting of well-dispersed $\alpha$-alumina suspensions followed by heating at $1073 \mathrm{~K}$. The relative density of the calcined bo- 


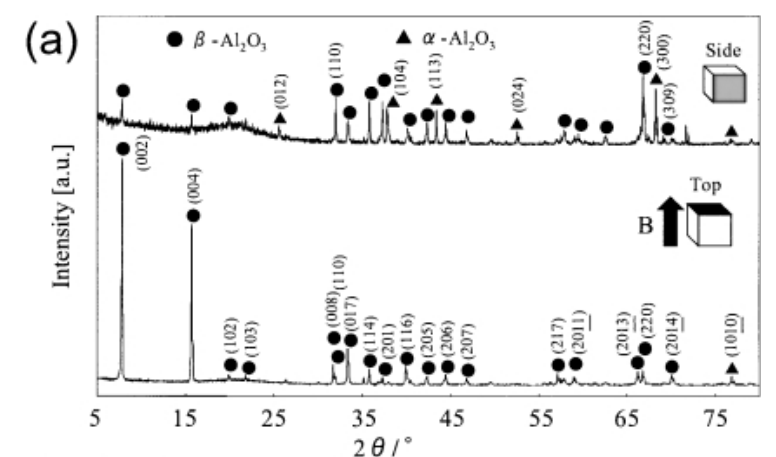

(b)

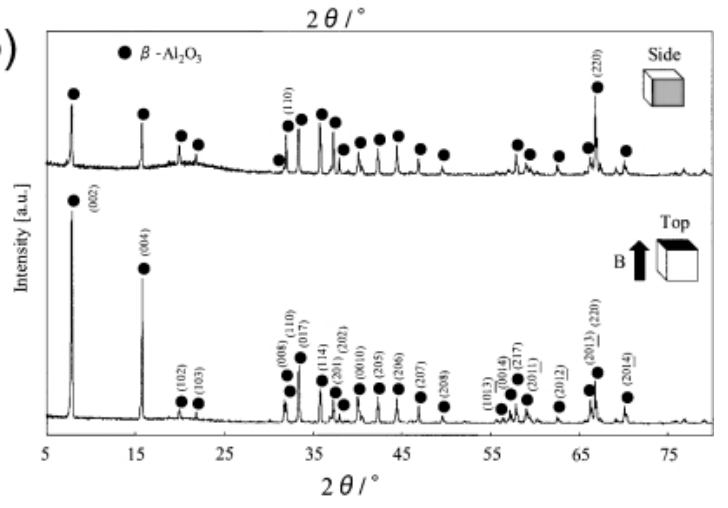

Fig. 23. XRD patterns of the products reaction sintered at $1700^{\circ} \mathrm{C}$ for the oriented $\alpha$-alumina green bodies infiltrated with $\mathrm{Na}_{2} \mathrm{O}$ and $\mathrm{MgO}$ for the conditions of $\mathrm{Na}_{2} \mathrm{O}: \mathrm{MgO}=1: 0.1$ with (a) no added polymer, and (b) added polymer.

dies without polymer addition was $60.7 \%$, but that with the polymer addition ${ }^{61)}$ decreased to $55 \%$. Figure 23 shows the XRD patterns of the infiltrated porous bodies initially with and without polymer addition and reaction sintering at $1973 \mathrm{~K}$. The sample was confirmed to be $\beta$-alumina by the reaction of $\alpha$-alumina and $\mathrm{Na}_{2} \mathrm{O}$, but $\alpha$-alumina did remain when the polymer particle was not added to alumina, but when the polymer was added, the residual $\alpha$-alumina decreases. It is noted that the amount of remaining $\alpha$-alumina decreased and single phase $\beta$-alumina was prepared for the samples with polymer addition. From Fig. 23, it appears that on the top plane perpendicular to the magnetic field, the diffraction peaks of the (004) and (008) ( $\beta$-alumina) and (1010) ( $\alpha$-alumina) planes at the interplanar angle of $17.5^{\circ}$ with the basal plane are very large. In contrast, on the side plane parallel to the magnetic field, the peaks of the (110) and (220) ( $\beta$-alumina) and (300) ( $\alpha$-alumina) planes are very large. These results indicate that a crystalline texture with the $c$-axis perpendicular to the magnetic field was developed by slip casting in the high magnetic field followed by reaction sintering.

We have successfully prepared a textured $\beta$-alumina by infiltration treatment with $\mathrm{Na}^{+}$and $\mathrm{Mg}^{2+}$ followed by reaction sintering of the oriented porous $\alpha$-alumina produced by slip casting in a high magnetic field.

\section{Concluding remarks}

We have achieved the production of highly textured microstructures of undoped and doped dense alumina by slip casting in a high magnetic field and subsequent heating. The degree of orientation depends on the processing factors such as heating temperature, particle size, magnetic field, viscosity of the suspension, etc. This process technique confers several advantages and it is possible for this type of processing to be applied to other non-cubic feeble magnetic ceramics such as diamagnetic or paramagnetic ceramics. However, special attention is necessary when we use whiskers or needle particles due to the large gravity energy.

Recently highly microstructure controlled ceramics are required to improve the mechanical, chemical, physical properties. Especially, a lot of efforts have been paid for obtaining highly textured ceramics, such as thermoelectric, dielectric, piezoelectric, thermal conducting ceramics. ${ }^{62)}$ The electrophoretic deposition (EPD) is known to be an attractive colloidal processing for producing film, laminated, functionally graded ceramics. The EPD can be conducted in a high magnetic field and crystalline-textured controlled laminated composites can be fabricated by varying the angle between the vectors of electric field and magnetic field. ${ }^{63)-67)} \mathrm{We}$ expect that the processing in a high magnetic field will be developed and be adopted in commercial products.

Acknowledgements The authors acknowledge the valuable discussions with Prof. K. Kitazawa, Prof. S. Asai, Prof. T. Kimura, Prof. K. Uematsu, Dr. T. Uchikoshi and Dr. N. Hirota. This study was supported in part by the Budget for Nuclear Research, and the Grant-in-Aid for Scientific Research of the Japanese Ministry of Education, Culture, Sports, Science and Technology.

\section{References}

1) Suvaci, E. and Messing, G. L., J. Am. Ceram. Soc., Vol. 83, pp. 2041-2048 (2000).

2) Hirao, K., Ohashi, M., Brito, M. and Kanzaki, S., J. Am. Ceram. Soc., Vol. 78, pp. 1687-1690 (1995).

3) Takenaka, T. and Sakata, K., Jpn. J. Appl. Phys., Vol. 19, pp. 31-39 (1980).

4) Yoshizawa, Y., Toriyama, M. and Kanzaki, S., J. Am. Ceram. Soc., Vol. 84, pp. 1392-1394 (2001).

5) Kimura, T., Holmes, M. H. and Newnham, R. E., J. Am. Ceram. Soc., Vol. 65, pp. 223-226 (1982).

6) Hong, S. H. and Messing, G. L., J. Am. Ceram. Soc., Vol. 82, pp. 867-872 (1999).

7) Suvaci, E., Oh, K.-S. and Messing, G. L., Acta Mater., Vol. 49, pp. 2075-2081 (2001).

8) Ma, Y. and Bowman, K. J., J. Am. Ceram. Soc., Vol. 74, pp. 2941-2944 (1991).

9) Brandon, D., Chen, D. and Chan, H., Mater. Sci. Eng., Vol. A195, pp. 189-196 (1995).

10) Uyeda, C., Jpn. J. Appl. Phys., Vol. 32, pp. L268-L270 (1993).

11) Beaugnon, E. and Tournier, R., Nature, Vol. 349, pp. 470-470 (1991).

12) de Rango, P., Lees, M., Lejay, P., Sulpice, A., Tournier, R., Ingold, M., Germi, P. and Pernet, M., Nature, Vol. 349, pp. 770-770 (1991).

13) Sassa, K., Morikawa, H. and Asai, S., J. Japan Inst. Met., Vol. 61, pp. 1283-1287 (1997).

14) Hirota, N., Honma, T., Sugawara, H., Kitazawa, K., Iwasaka, M., Ueno, S., Yokoi, H., Kakudate, Y., Fujiwara, S. and Kawamura, M., Jpn. J. Appl. Phys., Vol. 34, pp. L991-L993 (1995).

15) Asai, S., Sassa, K. and Tahashi, M., Sci. Technol. Adv. Mater., Vol. 4, pp. 455-460 (2003).

16) Kimura, T., Polymer J., Vol. 35, pp. 823-843 (2003).

17) Waki, N., Sassa, K. and Asai, S., Tetsu-to-Hagane, Vol. 86, pp. 363-369 (2000) [in Japanese].

18) Gaucherand, F. and Beaugnon, E., Phys. B, Vol. 294-295, pp. 96-101 (2001).

19) Yasuda, H., Tokieda, K. and Ohnaka, I., Mater. Trans., JIM, Vol. 41, pp. 1005-1021 (2000).

20) Taniguchi, T., Sassa, K. and Asai, S., Mater. Trans., JIM, Vol. 41, pp. 981-984 (2000).

21) Tahashi, M., Ishihara, M., Sassa, K. and Asai, S., Mater. 
Trans., Vol. 44, pp. 285-289 (2003).

22) Awaji, S., Watanabe, K., Ma, Y. and Motokawa, M., Phys. B, Vol. 294-295, pp. 482-485 (2001).

23) Ohtsuka, H., Xu, Y. and Wada, H., Mater. Trans., Vol. 41, pp. 907-907 (2000).

24) Suzuki, T. S., Otsuka, H., Sakka, Y., Hiraga, K. and Kitazawa, K., Jpn. J. Powder Powder Met., Vol. 47, pp. 1010-1014 (2000) [in Japanese].

25) Suzuki, T. S., Sakka, Y. and Kitazawa, K., Adv. Eng. Mater., Vol. 3, pp. 490-492 (2001).

26) Sakka, Y., Suzuki, T. S. and Hiraga, K., Key Eng. Mater., Vol. 224-226, pp. 619-622 (2002).

27) Sakka, Y. and Suzuki, T. S., Key Eng. Mater., Vol. 206-213, pp. 349-352 (2002).

28) Suzuki, T. S., Sakka, Y. and Kitazawa, K., J. Ceram. Soc. Japan, Vol. 109, pp. 886-890 (2001).

29) Suzuki, T. S. and Sakka, Y., Key Eng. Mater., Vol. 264-268, pp. 245-248 (2004).

30) Suzuki, T. S., Sakka, Y. and Kitazawa, K., IEEE Trans. Appl. Superconductivity, Vol. 14, pp. 1584-1587 (2004).

31) Suzuki, T. S. and Sakka, Y., Jpn. J. Appl. Phys., Vol. 41, pp. L1272-L1274 (2002).

32) Sakka, Y., Suzuki, T. S., Tanabe, N., Asai, S. and Kitazawa, K., Jpn. J. Appl. Phys., Vol. 41, pp. L1416-L1418 (2002).

33) Suzuki, T. S. and Sakka, Y., Chem. Lett., pp. 1204-1205 (2002).

34) Inoue, K., Sassa, K., Yokogawa, Y., Sakka, Y., Okida, M. and Asai, S., Mater. Trans., Vol. 44, pp. 1133-1137 (2003).

35) Suzuki, T. S. and Sakka, Y., Key Eng. Mater., Vol. 248, pp. 191-194 (2003).

36) Makiya, A., Kusano, D., Tanaka, S., Uchida, N., Uematsu, K., Kimura, T. and Kitazawa, K., J. Ceram. Soc. Japan, Vol. 111, pp. 702-704 (2003).

37) Li, S., Sassa, K. and Asai, S., J. Am. Ceram. Soc., Vol. 87, pp. 1384-1387 (2004).

38) Suzuki, T. S. and Sakka, Y., unpublished data (submitted to Patents).

39) Lange, F. F., J. Am. Ceram. Soc., Vol. 72, pp. 3-15 (1989).

40) Sakka, Y. and Hiraga, K., Nippon Kagaku Kaishi, pp. 497-508 (1999).

41) Cesarano, J., III, Aksay, I. A. and Bleier, A., J. Am. Ceram. Soc., Vol. 71, pp. 250-255 (1988).

42) Hirata, Y., Kamikakimoto, J., Nishimoto, A. and Ishihara, Y., J. Ceram. Soc. Japan, Vol. 100, pp. 7-12 (1992).

43) Tang, F., Ozawa, K., Uchikoshi, T. and Sakka, Y., J. Ceram. Soc. Japan, Suppl., Vol. 112, pp. S950-S953 (2004).

44) Suzuki, T. S., Sakka, Y., Nakano, K. and Hiraga, K., Mater. Trans. JIM, Vol. 39, pp. 689-692 (1998).

45) Suzuki, T. S., Sakka, Y., Nakano, K. and Hiraga, K., J. Am.
Ceram. Soc., Vol. 84, pp. 2132-2134 (2001).

46) Uyeda, C., Tanaka, K., Takashima, R. and Sakakibara, M. Jpn. J. Appl. Phys., Vol. 43, pp. 980-984 (2004).

47) Makiya, A., Shouji, D, Tanaka, S., Uchida, N., Kimura, T. and Uematsu, K., Key Eng. Mater., Vol. 206-213, pp. 445-448 (2002).

48) Tanaka, S., Chiu, C. P., Togashi, Y. and Uematsu, K., J. Ceram. Soc. Japan, Vol. 112, pp. 114-116 (2004).

49) Guilmean, E., Chateigner, D., Suzuki, T. S., Sakka, Y., Henrist, C. and Oulanddiaf, B., Chem. Mater. (in press).

50) Lotgering, F. K., J. Inorg. Nucl. Chem., Vol. 9, pp. 113-113 (1959).

51) Kim, Y.-M., Hong, S.-H. and Kim, D.-Y., J. Am. Ceram. Soc., Vol. 83, pp. 2809-2812 (2000).

52) "Fine Ceramics Handbook," ed., Fine Ceramics Handbook, Gihodo (1987) pp. 42-43 [in Japanese].

53) Sakka, Y. and Suzuki, T. S., Key Eng. Mater., Vol. 280-283, pp. 721-728 (2005).

54) Hori, S., Kurita, R., Yoshimura, M. and Sōmiya, S., J. Mater. Sci. Lett., Vol. 4, pp. 1067-1070 (1985).

55) Alexander, K. B., Becher, P. F., Waters, S. B. and Bleier, A., J. Am. Ceram. Soc., Vol. 77, pp. 939-946 (1994).

56) Tahashi, M., Sassa, K., Hirabayashi, I. and Asai, S., Mater. Trans. JIM, Vol. 41, pp. 985-990 (2000).

57) Hirata, Y., Nakagame, S. and Ishihara, I., J. Mater. Res., Vol. 5, pp. 640-646 (1990).

58) Hirata, Y., Haraguchi, I. and Ishihara, I., J. Mater. Res., Vol. 7, pp. 2572-2578 (1992).

59) Sakka, Y., Honda, A., Suzuki, T. S. and Moriyoshi, Y., Solid State Ionics, Vol. 172, pp. 341-347 (2004).

60) Hirata, Y. and Izaku, T., J. Ceram. Soc. Japan, Vol. 101, pp. 263-263 (1993).

61) Tang, F., Fudouzi, H. and Sakka, Y., J. Am. Ceram. Soc., Vol. 86, pp. 2050-2054 (2003).

62) Sano, M., Horii, S., Matsubara, I., Funahashi, R., Shikano, M., Shimoyama, J. and Kishio, K., Jpn. J. Appl. Phys., Vol. 42, pp. L198-L200 (2003).

63) Uchikoshi, T., Suzuki, T. S., Okuyama, H. and Sakka, Y., J. Mater. Res., Vol. 19, pp. 1487-1491 (2004).

64) Uchikoshi, T., Suzuki, T. S., Okuyama, H., Sakka, Y. and Nicholson, P. S., J. Eur. Ceram. Soc., Vol. 24, pp. 225-229 (2004).

65) Uchikoshi, T., Suzuki, T. S., Okuyama, H. and Sakka, Y., J. Mater. Res., Vol. 18, pp. 254-256 (2003).

66) Uchikoshi, T., Suzuki, T. S., Okuyama, H. and Sakka, Y., J. Mater. Sci., Vol. 39, pp. 861-865 (2004).

67) Uchikoshi, T., Suzuki, T. S., Tang, F., Okuyama, H. and Sakka, Y., Ceramic Inter., Vol. 30, pp. 1975-1978 (2004). 